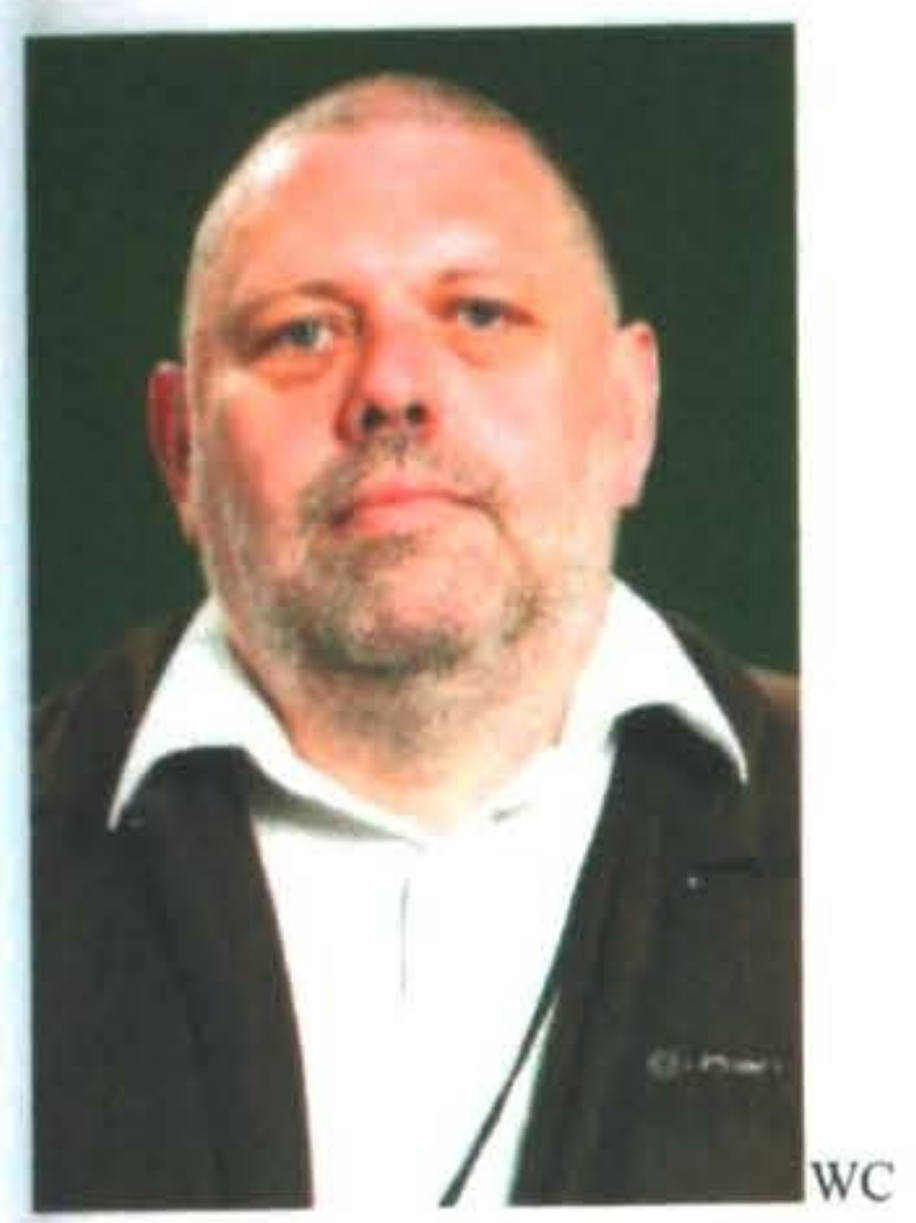

\title{
REGIONAL LABOUR MARKET ADJUSTMENT AND SOCIAL SECURITY BENEFIT UPTAKE
}

\author{
William Cochrane \\ Department of Societies and Cultures \\ University of Waikato \\ Jacques Poot \\ Population Studies Centre \\ University of Waikato
}

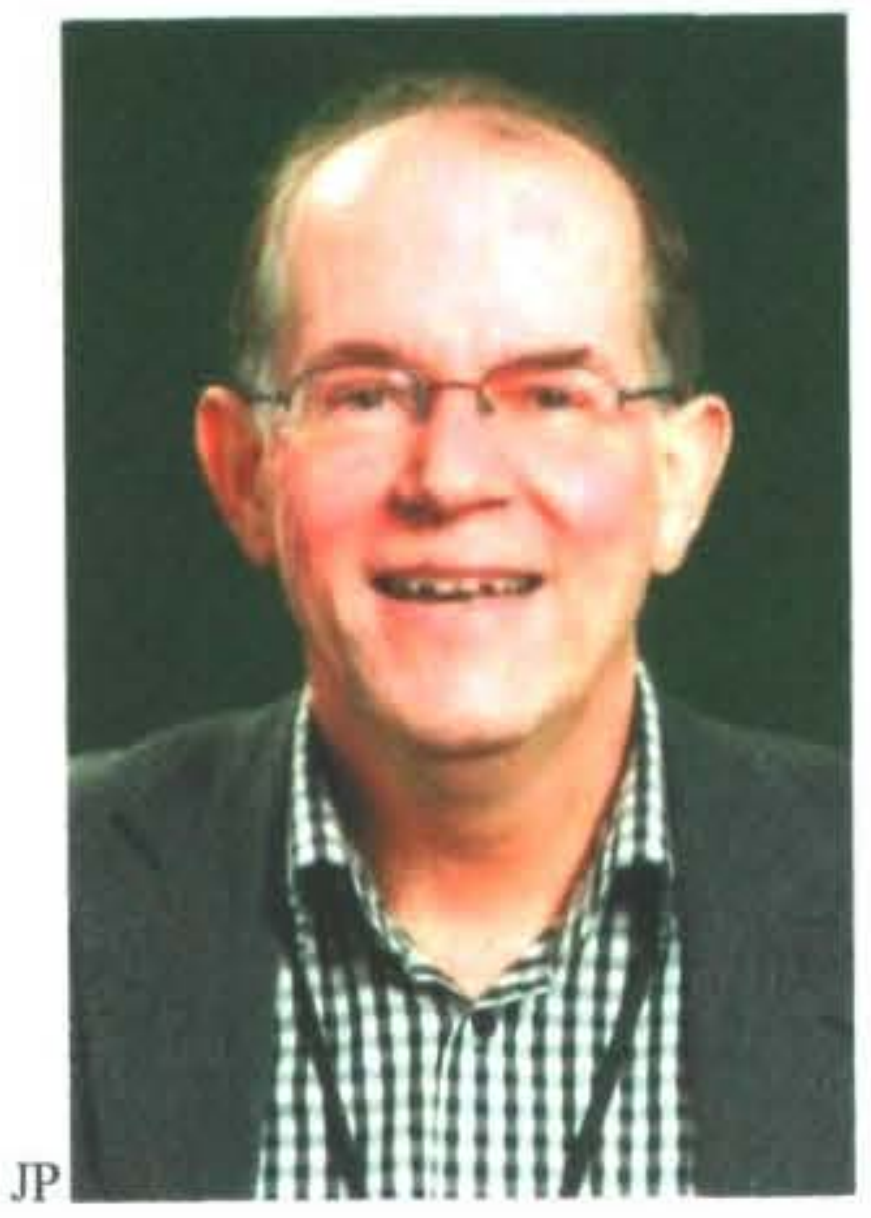

\begin{abstract}
In many countries there is significant hidden unemployment among low-skilled older workers receiving long-term social security benefits. International research has shown that there is an important regional dimension to this phenomenon. Particularly in peripheral regions, the types of jobs that are being created may not offer opportunities for older, less skilled, and less mobile workers. In this paper we analyze the determinants of regional variation in social security benefit uptake in New Zealand by category (viz. unemployment, sickness, invalids and domestic purposes) during the period 1996-2006 using a panel of data drawn from the five-yearly Census of Population and Dwellings aggregated to functionally-defined local labour market areas (LMAs). We find that across LMAs there is geographical clustering in benefit uptake. Ignoring this spatial correlation may lead to erroneous conclusions regarding the role of local conditions in explaining the regional variation in benefit uptake. We also account for spatial and temporal correlations in uptake across different types of benefits. However, there is little evidence of spatial heterogeneity. Hence national regression coefficients are informative for all LMAs. Benefit uptake generally increases with rising unemployment, but the post-2000 economic boom did not offset the secular trend of increasing numbers of invalids and sickness beneficiaries. The uptake of sickness and invalids benefits is greater, but quantitatively similar, in LMAs where the labour force is relatively older. Several other features of LMAs affect benefit uptake also, but their impact varies across benefit types.
\end{abstract}

\section{Introduction}

In many countries, governments have pursued policies to enhance labour market flexibility and reduce long-term unemployment. Such policies have contributed to improved labour market outcomes, although it is often difficult to separate out the effects of the policies from the impact of concurrent buoyant economic conditions. In any case, declines in official unemployment rates may coincide with increases in hidden unemployment, particularly among low-skilled older workers, who end up on long-term social security benefits, such as the sickness or invalids benefit, or who may (semi) retire after becoming unemployed.

International research has shown that there are large regional differences in the uptake of social security benefits, but formal econometric modelling of this spatial variation has to date been relatively limited (McVicar, 2006). There are many examples in the literature of regions in which certain traditional industries such as textile manufacturing, mining or agricultural produce processing were the primary source of employment until globalisation and the liberalisation of regional economies in recent decades led to significant contraction of such industries. Particularly older and low-skilled male workers, whose jobs vanished in this economic transformation process, have found it difficult to obtain employment in emerging knowledge-intensive sectors or female-dominated services. Geographic mobility of such workers tends to be low. The stresses of layoffs, job insecurity and unemployment often impact on physical and mental health of the older workers. Some form of incapacity benefit is then institutionally (through implicit understandings between employers, medical practitioners and social security providers) seen as a preferred outcome compared with long-term unemployment. This is particularly the case in peripheral regions. The example of mining towns in the UK, where hidden unemployment remains extensive, is well documented in the literature (e.g., Beatty et al. 2007).

In New Zealand, the number of people receiving the unemployment benefit halved between 2001 and 2006, as a result of buoyant economic conditions leading to a high rate of job creation (see Figure 1). Similarly, the number of persons (primarily females) receiving the domestic purposes benefit (DPB) dropped by 12 percent. Yet at the same time there was a sharp increase of one third in the number receiving the sickness benefit and a growth in the 
number receiving the invalids' benefit of 11.6 percent and 18.6 percent for males and females respectively. This cannot be explained by deterioration in the health of the population. Appropriate measures, such as independent life expectancy which measures the expected number of years of life free from functional limitations requiring assistance, have shown significant improvement between 1996 and 2006 (e.g., MSD, 2008).

Instead, a simple explanation at the macro-level of this apparent paradox, of measured unemployment declining and population health improving in the upswing of the business cycle, but incapacity benefit uptake concurrently increasing, is that periods of rapid job creation coincide with an asymmetry in inflows into and outflows from non-participation. Job creation leads to a reducing flow from employment into all forms of non-participation, including retirement and incapacity benefit enrolment. Job creation also leads to an increase in the flow from unemployment into jobs, but the flow from the sickness and invalid benefit rolls into jobs is far less responsive to the upswing in the business cycle, given that benefit receipt does not require active job search and the net financial gains from employment may be relatively little for beneficiaries with low skill levels.

At the regional level, the outcomes in terms of nonparticipation and benefit uptake will depend on compositional factors with respect to the characteristics of the population and the local labour market, including health-related factors (see, e.g., Pool et al. 2006b), but also on institutional factors, as there may be some regionally-specific variation in implementation of policies, even within a nationally determined framework. This could lead to so-called spatial heterogeneity in the form of the coefficients that measure the impact of local economic conditions on benefit uptake varying across regions. In addition, geography may also matter, in terms of labour market outcomes in surrounding local labour markets having an impact on local wage setting and geographic mobility in any particular region. This is referred to as spatial dependence.

Figure 1: Social security benefit uptake as a percentage of the working age population, 1986-2007.

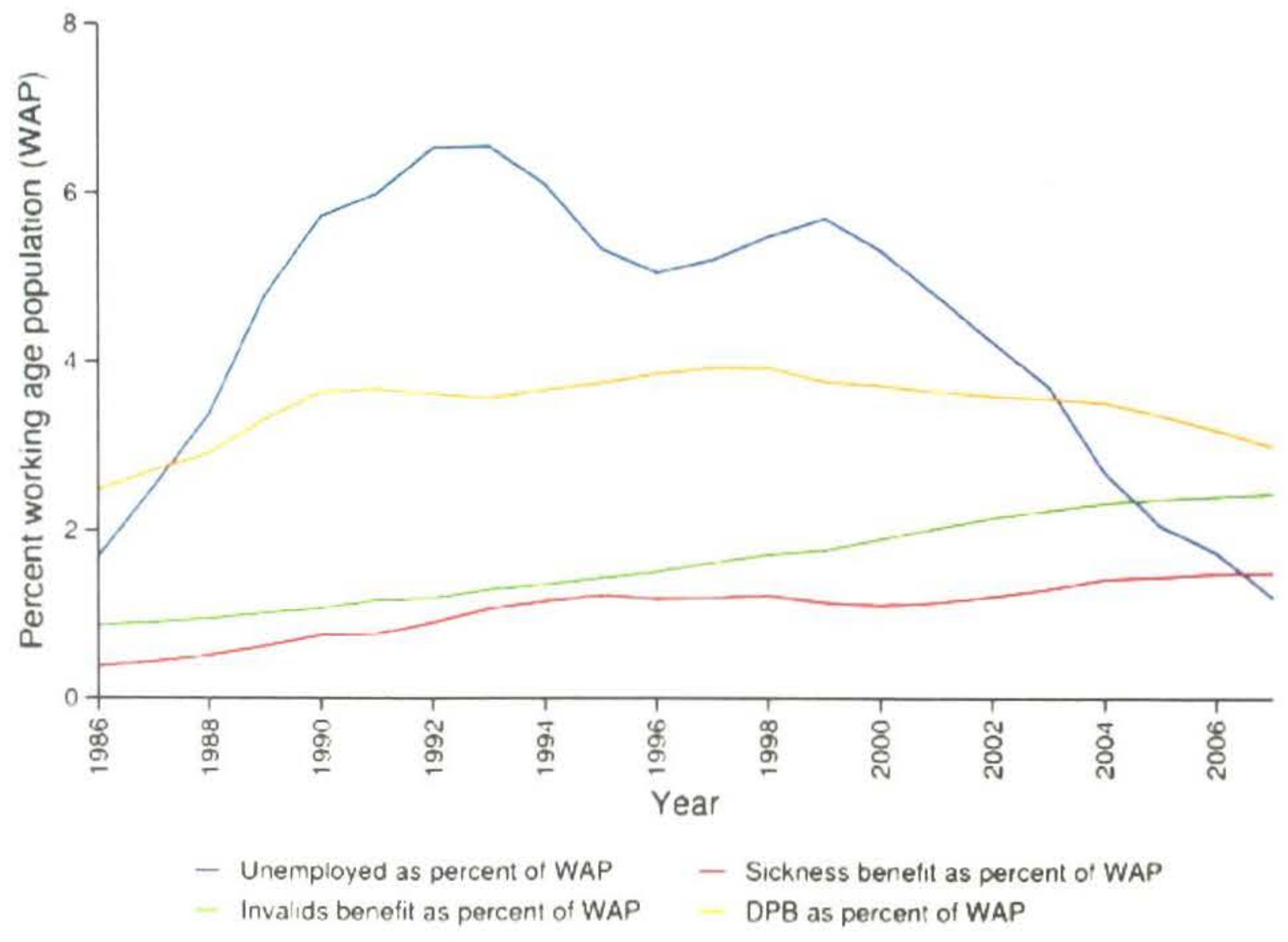

The present paper analyses the determinants of regional benefit usage by category (viz., unemployment, sickness, incapacity and single parents caring for dependent children) in New Zealand using a panel of data drawn from the five-yearly Census of Population and Dwellings aggregated to 58 functionally defined local labour market areas (LMAs). No attempts are made to identify the "best" specification for a particular type of benefit usage. Instead, the same regression model is applied to all four benefit types. Three waves of census data (1996, 2001 and 2006) are used for estimation, with additionally 1991 data used where lagged variables are required to model 1996 benefit uptake.
The theoretical framework that drives the specification of the panel model takes account of changes in the level and structure of the demand for labour, the composition of the labour force and institutionally determined factors such as benefit replacement rates and changes in eligibility rules. This framework builds on, for example, research by Beatty et al. (2000) in the UK and by Bartik (2002) in the US.

Preliminary analysis of New Zealand social security data, using time series of social welfare data, rather than census data, indicated that the buoyant economic conditions of the new millennium years up to 2004 benefitted all 
regions, but not all workers, and comparable workers in different regions often in different ways (Baxendine et al. 2005). Nonetheless, there appeared to be some spatial convergence in aggregate benefit uptake outcomes across LMAs for younger people: peripheral regions with high aggregate benefit uptake rates in the 1990s among workers under the age of 40 experienced the greatest declines in these rates during the subsequent economic boom. Overall, however, regional dispersion in benefit uptake rates has been steadily increasing across New Zealand regions since 1986 (see Pool et al., 2006a, Table 4) and the descriptive statistics reported below show that this trend has continued since 2001 .

The next section describes the trends and regional variation in the rates of benefit uptake. The third section motivates the variables that are used in the econometric modelling. This is followed by a section with regression results. The last section sums up.

\section{New Zealand Regional Data}

The data for our analysis were obtained from the quinquennial New Zealand Census of Population and Dwellings 1991, 1996, 2001 and 2006. The Labour
Market Area (LMA) data have been built up from Census Area Unit (CAU) level and made available for this research by Motu Economic and Public Policy Research. It has long been recognised that functional economic areas are the most appropriate unit of analysis for examining regional economic activity (Stabler and Olfert, 1996 , p. 206), because boundaries of administrative areas such as Regional Council regions or territorial authorities often do not represent boundaries of economic activities and interactions.

Consequently, there has been growth in the use of functional economic areas, notably in the analysis of various labour market phenomena (see Cochrane and Poot, 2007). Newell and Papps (2001) used travel to work data from the 1991 and 2001 censuses to define LMAs in New Zealand. This research yielded 140 LMAs for 1991 and 106 for 2001. This level of breakdown is too refined for linking to regional characteristics that come from sources other than the census. A level of disaggregation that permits the building up of a regional analysis with a wide range of regional indicators is that of 58 LMAs. The boundaries and names of these LMAs are shown in Cochrane and Poot (2007).

Table 1: New Zealand social security benefits and eligibility criteria.

\begin{tabular}{|c|c|}
\hline Benefit & Eligibility \\
\hline Unemployment & $\begin{array}{l}\text { - Need to be aged } 18 \text { or over, or aged } 16-17 \text { and living with a partner and children who are supported by } \\
\text { the applicant } \\
\text { - Not be working full-time, but actively looking for a full-time job } \\
\text { - Able to start work now }\end{array}$ \\
\hline Sickness & $\begin{array}{l}\text { - In a job now, but have had to stop working or reduce hours and income because of sickness, injury, } \\
\text { pregnancy or disability, or } \\
\text { Unemployed or working part-time, and finding it hard to look for and do full-time work because of } \\
\text { sickness, injury, pregnancy or disability }\end{array}$ \\
\hline Invalids & $\begin{array}{l}16 \text { or over and: } \\
\text { - Unable to regularly work } 15 \text { hours or more a week because of a sickness, injury or disability which is } \\
\text { expected to last at least } 2 \text { years; or } \\
\text { Life expectancy is expected to be less than } 2 \text { years and the applicant is unable to regularly work } 15 \\
\text { hours or more a week; or } \\
\text { Blind with a specified level of restriction in the visual field or in the sharpness of vision }\end{array}$ \\
\hline $\begin{array}{l}\text { Domestic } \\
\text { Purposes }\end{array}$ & $\begin{array}{l}\text { - A parent of a child under } 18 \text { who is dependent on the applicant and } \\
\text { - the applicant is not living with the other parent or a partner and } \\
\text { - has lost the support of, or is not being adequately maintained by a partner and } \\
\text { - aged } 18 \text { or over (or } 16-17 \text { if legally married or in a civil union before separation). }\end{array}$ \\
\hline
\end{tabular}

See http://www.winz.govt.nz/get-assistance/main-benefit/ for further details.

The New Zealand social welfare system provides for four major transfer payments for the eligible working age population: the unemployment benefit, the sickness benefit, the invalids benefit and the DPB. A brief description of the eligibility criteria for each benefit is contained in Table 1. These taxable benefits are statutory rights as opposed to insurance-based payments with eligibility continuing as long as a person meets the eligibility criteria and is under 65 , at which point eligibility for New Zealand Superannuation commences.
The latter benefit is a non-means tested non-contributory payment made to virtually all residents (except recent migrants) aged 65 and over, with the gross payment for a single person being around 50 percent of the median wage. The level of payment available with each of the four social security benefits is also modest relative to the median wage and benefit levels were reduced markedly in value in the early 1990s (see e.g. Stephens, 1992 for details), although provision exists to supplement these payments through various additional allowances for 
hardship, accommodation and the like. In addition, beneficiaries with children may be eligible for the

Figure 2: Box plots of benefit receipt rates

(a) Unemployment benefit
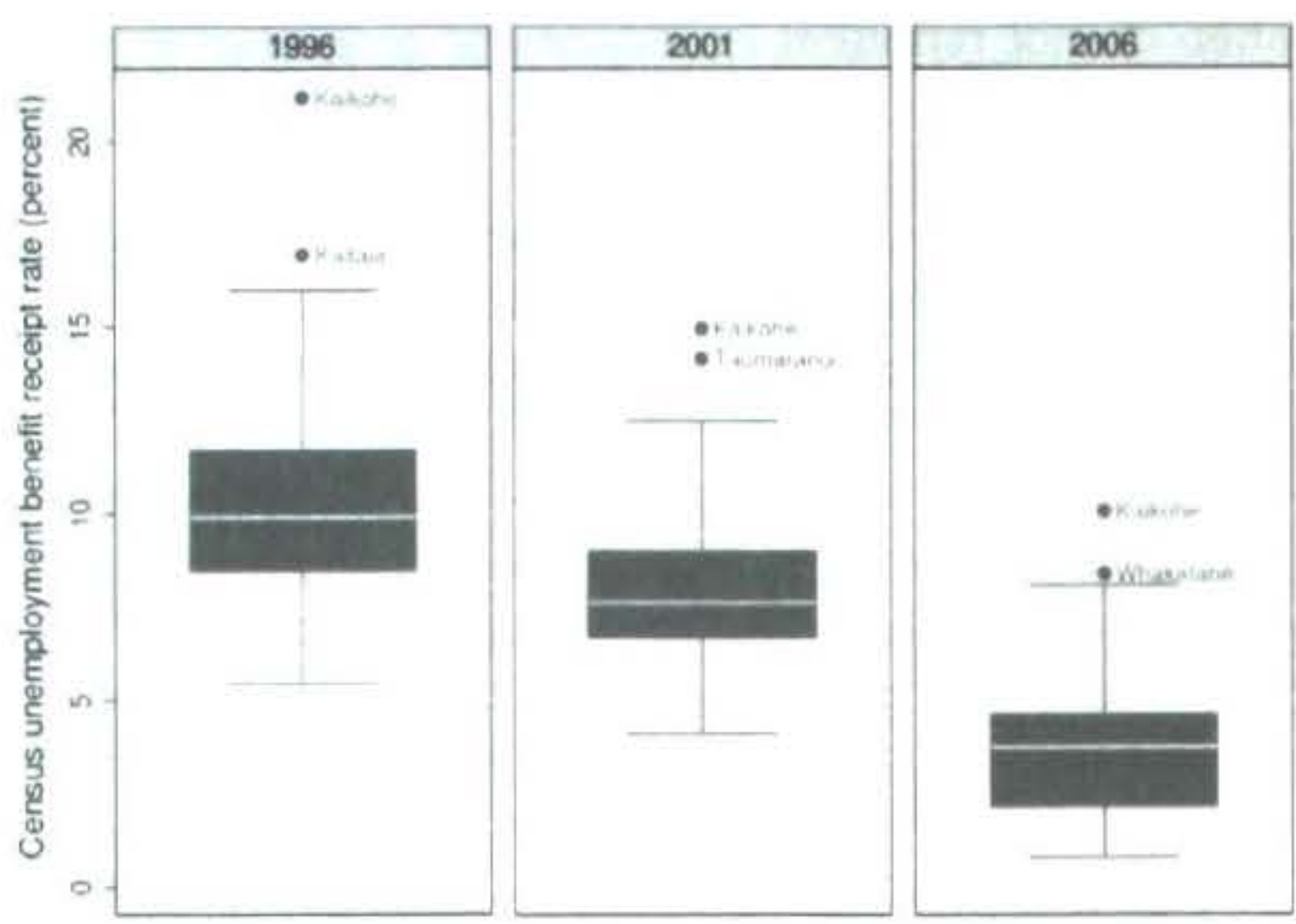

(c) Invalids benefit
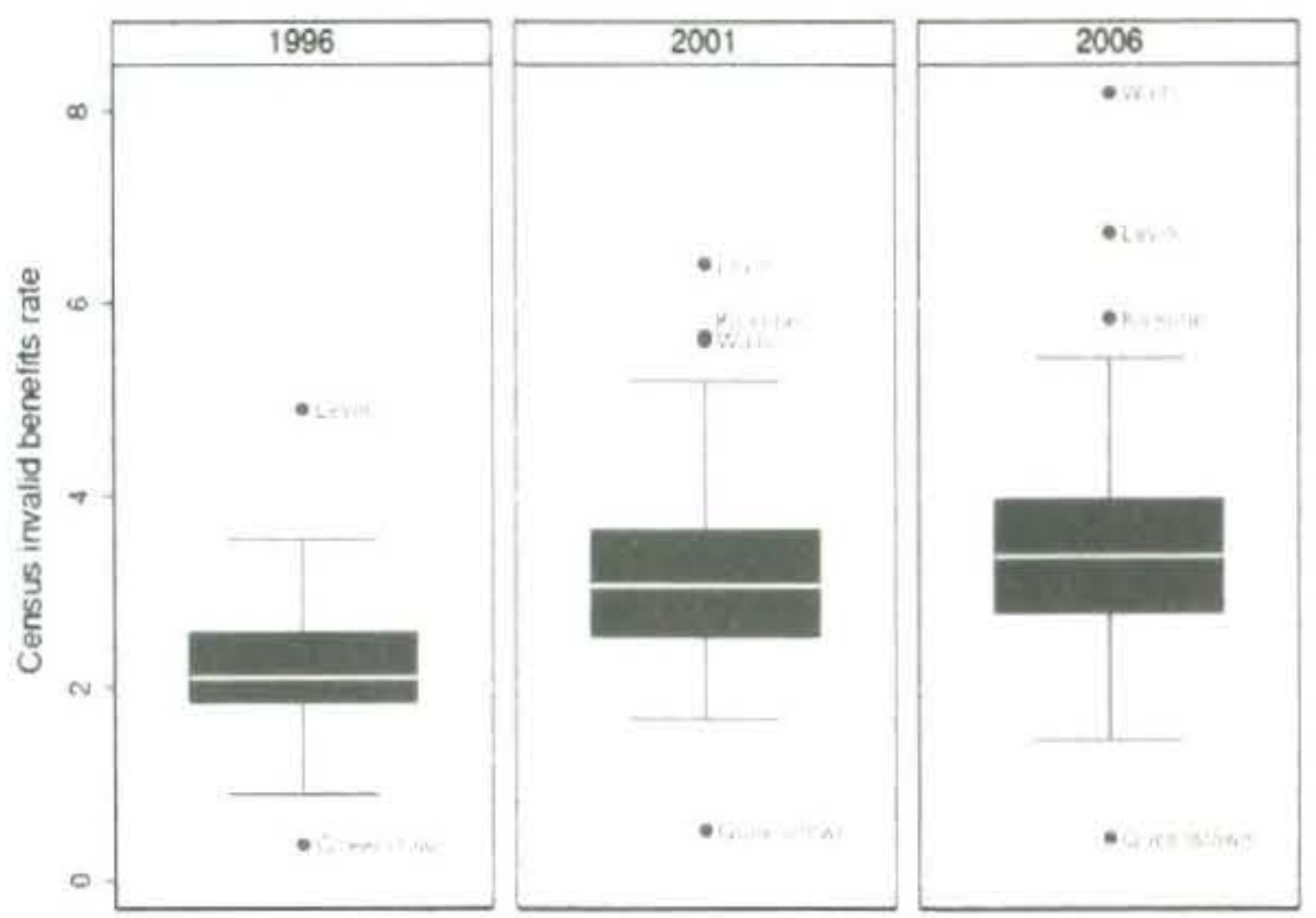

Figure 2 shows the distribution of benefit receipt rates across LMAs in 1996, 2001 and 2006 in the form of box plots. The black boxes represent the interquartile range (IQR), with the median represented by the horizontal lines inside. Outliers (more than 1.5 IQR beyond the first and third quartile) are individually labelled. The "whiskers" are the smallest and largest observations within 1.5 IQR of the first and third quartile (see Tukey, 1977). Summary statistics are reported in Table 2 . The median LMA unemployment benefit rate (those who received the unemployment benefit at some stage during the previous twelve months divided by the population aged 15 to 64 ) reduced by more than half over the decade, from 9.9 percent to 3.5 percent. At the same time, the median LMA invalids benefit rate increased from 2.1 percent of the population to about 3.3 percent, an increase of more than half. The median LMA sickness benefit rate decreased slightly about 0.3 percentage points from 2.6 percent in 1996 to 2.3 percent in 2001 before increasing again back to 2.6 percent in 2006. Lastly, the median
'Working for Families Tax Credit'.

(b) Sickness benefit

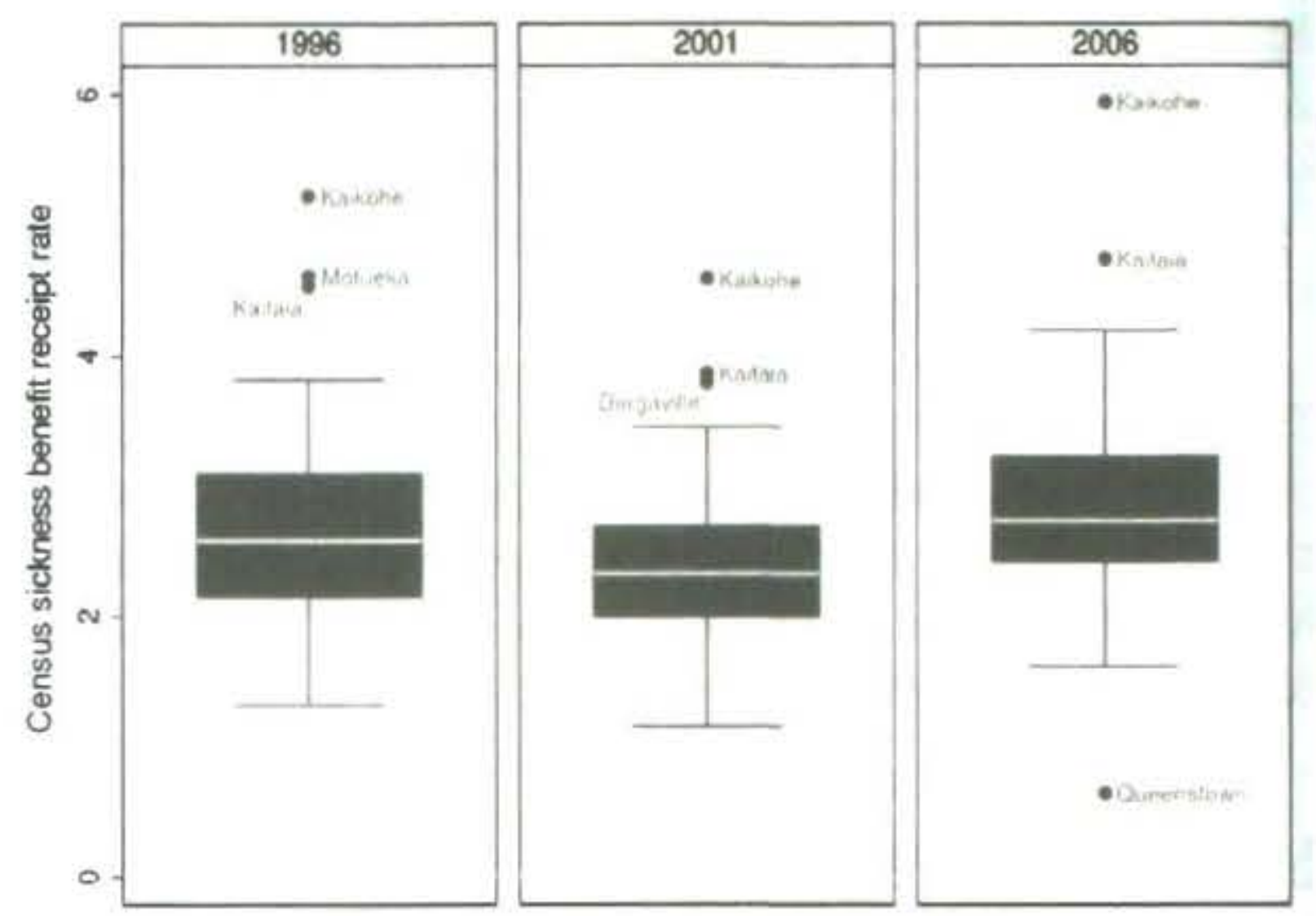

(d) Domestic purposes benefit

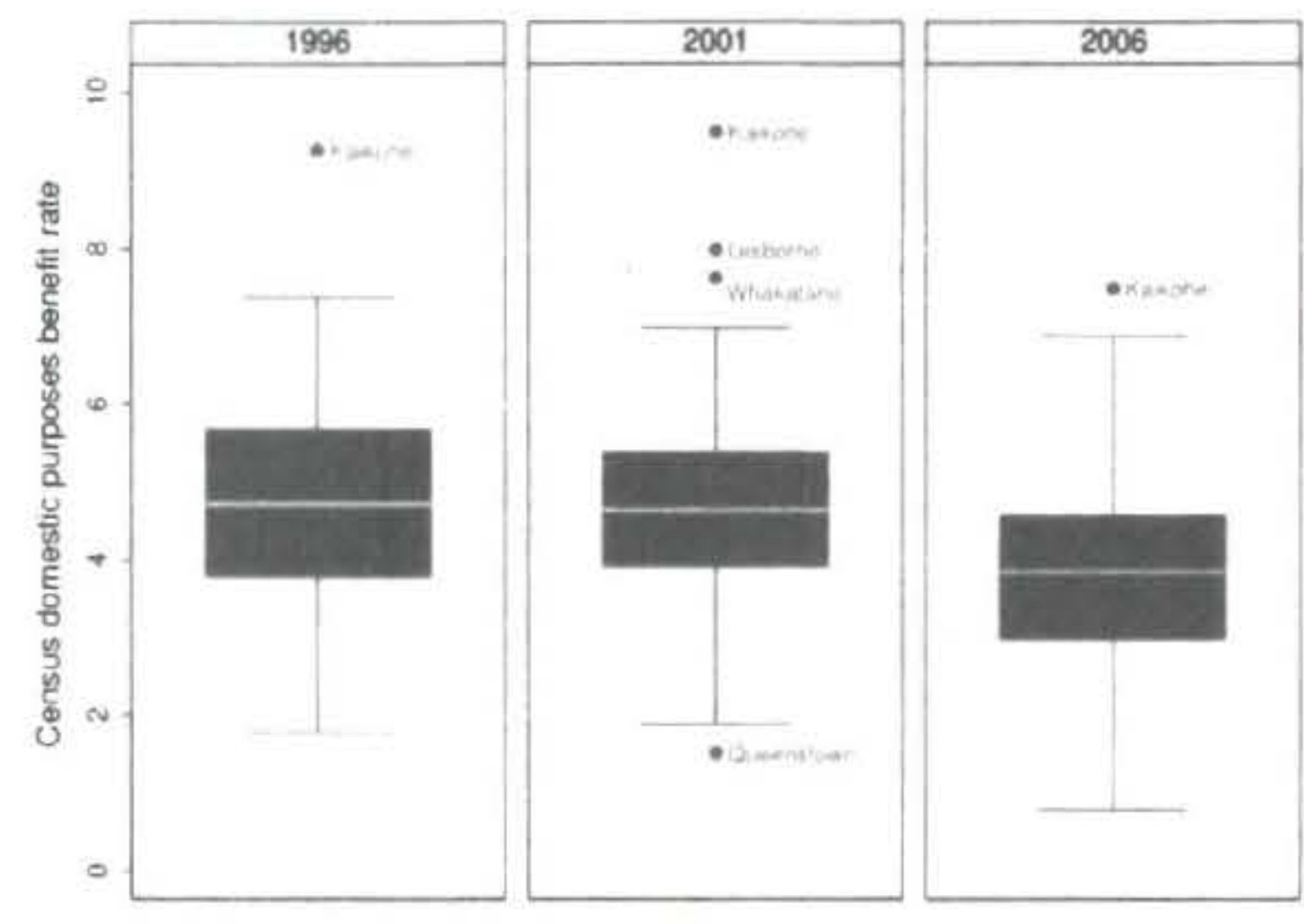

LMA DPB rate fell by 0.9 percentage points over the decade to a rate of about 3.8 percent in 2006 .

Looking at the dispersion of values for each of the benefit rates over the decade, as measured by the coefficient of variation $(\mathrm{CV})$ in Table 2, there is evidence of increasing dispersion over the 2001-2006 sub-period for all benefit types (the IQR values, which are not reported in the table, show the same trend). During the previous quinquennium, however, dispersion had increased in the case of the invalids benefit and DPB rate, but decreased in the case of the unemployment benefit rate and the sickness benefit rate. Certainly, with respect to the invalids benefit rate, the long-term regional divergence earlier identified by Pool et al. (2006a) has been reinforced by the post 2001 change.

To explore determinants of the interregional and temporal variation in LMA benefit uptake rates, a range of variables were selected to capture various features of the regional labour market. The approach adopted here is not to find the best possible model for any given type of 
benefit uptake, but to instead consistently apply the same set of variables to all benefit rate regression equations and to compare differences in estimates across equations.

Given that the structure of our data is in the form of pooled cross sections of averages of each variable for each LMA, it is well known that even the fixed effects estimator (which accounts for unmeasured time-invariant differences between LMAs) is inconsistent when some of the explanatory variables are endogenous (i.e. they are themselves affected by benefit uptake). This is usually addressed in the literature by introducing variables that are known to correlate with the endogenous regressors, but which themselves are unaffected by benefit uptake (see, e.g., Vella and Verbeek, 1999). Because such instruments are often not easy to find, we take the simple approach of lagging potentially endogenous variables and assuming that such lagged variables are uncorrelated with the current error terms in the regression models. Robust standard errors are calculated throughout.

Table 2: Descriptive statistics on LMA benefit uptake rates.

\begin{tabular}{cccc}
\hline $\begin{array}{c}\text { Census unemployment } \\
\text { benefit rate }\end{array}$ & $\begin{array}{c}\text { Census sickness } \\
\text { benefit rate }\end{array}$ & $\begin{array}{c}\text { Census invalids } \\
\text { benefit rate }\end{array}$ & $\begin{array}{c}\text { Census domestic } \\
\text { purposes benefit rate }\end{array}$ \\
\hline
\end{tabular}

\begin{tabular}{lcccc}
\hline \multicolumn{5}{c}{1996} \\
\hline Median & 9.92 & 2.58 & 2.10 & 4.72 \\
Mean & 10.32 & 2.68 & 2.23 & 4.83 \\
Minimum & 5.40 & 1.32 & 0.38 & 1.77 \\
Maximum & 21.13 & 5.22 & 4.89 & 9.26 \\
CV & 0.28 & 0.28 & 0.33 & 0.30 \\
\hline
\end{tabular}

\begin{tabular}{lcccc}
\hline \multicolumn{2}{c}{2001} & & \\
\hline Median & 7.60 & 2.39 & 2.23 & 4.76 \\
Mean & 7.91 & 2.39 & 3.23 & 4.76 \\
Minimum & 4.08 & 1.15 & 0.53 & 1.51 \\
Maximum & 14.95 & 4.58 & 6.41 & 9.49 \\
CV & 0.28 & 0.26 & 0.34 & 0.32 \\
\hline & & & & 3.81 \\
\hline Median & 3.52 & 2006 & 3.25 & 3.75 \\
Mean & 3.60 & 2.70 & 3.36 & 0.53 \\
Minimum & 0.53 & 0.43 & 0.30 & 7.37 \\
Maximum & 9.89 & 5.85 & 8.07 & 0.37 \\
CV & 0.53 & 0.32 & 0.39 & \\
\hline
\end{tabular}

\section{Determinants of Benefit Uptake at the LMA Level}

The variables used in this paper are listed in Table 3. Our primary conjecture is that benefit uptake is predominantly determined by the buoyancy of the local labour market. This is obvious with respect to unemployment benefit uptake, which will be high in LMAs where the local labour market is relatively slack, but it is also the case with respect to the other benefits where benefit uptake may constitute a form of hidden unemployment through the mechanism discussed in the introduction. Since the regression model incorporates only lagged economic conditions, a correlation between lagged unemployment (lagpue) and current benefit uptake across LMAs implies persistence over time in the ranking of LMAs with respect to unemployment rates, but this is indeed the case in most countries. Longhi et al. (2006) found that while wages tend to be 'sticky' over time, unemployment rates have high spatial persistence. Essentially, a positive effect of unemployment rates on benefit uptake captures the effects of hysteresis (Baddeley et al., 1998; Pehkonen \& Tervo, 1998).

Wilson et al. (2005) point to the impact of the age profile of the population on rates of uptake of the sickness and invalids benefits in the New Zealand context. They find that around half of the rise in the invalids benefit uptake is explained by population growth, the ageing of the population, and the rise in the age of eligibility for New Zealand Superannuation. A variable (lagpoldwork) is used to account for the age composition effect (with population growth controlled for by using uptake rates rather than levels, and superannuation eligibility changes captured by census year dummy variables).

The education variable (lagpnoqual) serves as a proxy for the extent to which the LMA's labour force is unskilled. 
It is well known that the low skilled have fared poorly in the contemporary labour market with rapidly declining demand for low-skilled workers being typical of many economies (Nickell and Bell, 1995; Goux and Maurin,
2000; Machin, 2001). As noted earlier, there are also strong indications of an inverse relationship between average skills levels and rates of benefit uptake (Black et al, 2002).

\section{Table 3: Explanatory variables in regression models of social security benefit uptake.}

\begin{tabular}{ll}
\hline Variable & Definition \\
\hline lagpue & $\begin{array}{l}\text { The percentage of the labour force unemployed and actively seeking work in an LMA } \\
\text { lagpoldwork }\end{array}$ \\
The percentage of persons aged 50-64 in an LMA \\
lagpnoqual & The percentage of persons aged 15 and over in an LMA reporting no qualifications \\
lagpoprop & The percentage of private dwellings in an LMA that are owner-occupied \\
net_mig & Net migration as a percentage of the LMA usually resident population \\
lagpservice & Persons employed in services as a percentage of total LMA employment \\
lagpsolo & Single parent families as a percentage of the total number of families in an LMA \\
lagpmaori & The percentage of the LMA population who declared in the census to be Māori \\
\hline
\end{tabular}

Note: all variables are measured by the previous census, except for net migration which refers to migration flows over the preceding intercensal period.

Wherever workers are more geographically mobile, for example when they are more highly qualified or younger, the impact of economic transformation on benefit uptake may be less. Besides considering age and skill composition, we therefore also take account of homeownership and the LMA's net migration. Oswald's work (e.g., 1996) on the relationship between homeownership and unemployment suggests that the costs that have to be incurred when selling a home in order to accept a job and buy a home in another region may be a disincentive to consider jobs outside the LMA and may therefore contribute to higher benefit uptake rates. Our own work on the Oswald hypothesis in the New Zealand context (Cochrane and Poot, 2007), using 1986 to 2001 census data, found some support for Oswald's conjecture. To test such as effect in the present context, we consider the percentage of private dwellings owned by the occupant (lagpoprop). In addition, it is possible to directly account for churning in the local labour market by incorporating the net migration rate over the preceding intercensal period (net_mig).

On the demand side. LMAs in which the share of employment in services in total employment is large may have been able to better absorb job losses from economic transformation and provide new employment to some benefit recipients. As with other developed economies, the majority of employment growth in the post 1991 period in New Zealand has been concentrated in the service sector. As an indicator of specialisation in industries that have experienced such growth, the percentage of employment in services (lagpservice) has been included.

The percentage of single parent families (lagpsolo) is included as single parenthood is a prime requirement for receipt of the DPB. There is also evidence of divorce or relationship dissolution leading to ill health (Richards et al, 1997), possibly leading to greater sickness and invalids benefit uptake. On the other hand, there is evidence that unemployment may trigger relationship dissolution, and consequently often single parenthood (see Kraft, 2001). This potential endogeneity of the single parent variable is at least partially controlled for by the adopted lag structure.

We also account for differences across LMAs in ethnic composition. Māori generally have poorer outcomes in the labour market in New Zealand than the Pakeha (European) majority (Chapple and Rea, 1998) and we take account of this by incorporating the proportion of the usually resident population that identify as Māori (lagpmaori). The New Zealand system of ethnic classification allows for an individual to identify with multiple ethnicities. Hence this construct should not be seen as denoting the proportion of those who see themselves as exclusively Māori. Of course, the statistical significance of lagpmaori may be a proxy for a number of unspecified determinants of labour market outcomes that disproportionally affect Māori rather than a genuine 'ethnic' effect, such as discrimination. In practice, both explanations may be valid and non-exclusive. The issue remains subject to debate (e.g. Gould, 2003). Caution is required in interpreting the regression results in this respect.

The dependent variables, the census unemployment benefit rate, sickness benefit rate, invalids benefit rate and the DPB rate have been calculated on the basis of the census question on sources of income. This question asks about all sources from which an individual aged 15 years and over received personal income in the 12 months ending 31 March. Hence it is not a point measure of the percentage of persons in receipt of a benefit on census day nor does it exclude the possibility that a person has moved between benefits or between a benefit and paid 
employment over the course of the year. Despite these drawbacks it would seem reasonable that these rates are indicative of the level of uptake of these benefits in a LMA. Further, whatever the shortcomings of this approach, no other source of this data is readily available at this regional level.

\section{Regression Model Results}

For each of the main four benefits considered, the selfreported proportion of persons receiving that benefit in the year previous to the census enumeration was regressed on the variables described above. Various estimation procedures were employed and compared. Due to space constraints, only one set of results is presented, namely those that account for spatial spillovers with respect to the individual benefit types, but also spatial and temporal correlations between benefit types. This estimator can be referred to as the Spatial Lag Seemingly Unrelated Regression model; or the SL-SUR model in short. Other estimators that were considered include standard pooled OLS estimation, the regional fixed effects estimator, the spatial lag model and the spatial error model. Robust standard errors were used to address heteroscedasticity arising from the markedly differing populations of the LMA. In qualitative terms, the results turned out to be quite similar across different econometric specifications (see Cochrane, 2010).

Nonetheless, OLS is not the appropriate estimator because each of the benefit uptake rates is likely to be spatially correlated, i.e. LMAs with high (low) uptake rates are likely to be surrounded by LMAs with similarly high (low) uptake rates. This can be formally shown by means of the Moran statistic, which turned out to be statistically significant at the 1 percent level for each of the four benefit types. In the presence of spatial autocorrelation, OLS generates inefficient and inconsistent coefficient estimates, with estimated standard errors being smaller than the correct standard errors (e.g. Arbia, 2006).

In addition to the deficiencies of the OLS estimator in the presence of spatial autocorrelation, this approach also fails to utilise the panel nature of the data. This is particularly serious in cases such as our application as it is highly unlikely that all the factors influencing the uptake of social security benefits are captured by the variables that we have available (listed in Table 3). As it is quite likely that some of the omitted variables will be correlated with the included variables, OLS will yield biased parameter estimates.

Given the difficulties that the presence of spatial dependence in data presents for the OLS estimator, a number of methods have been developed to account for spatial dependence. Commonly this is done in one of two ways. The first is spatial lag dependence, which pertains to spatial correlation in the dependent variable. The alternative is spatial error dependence in which the error terms are spatially correlated (Anselin, 1988). In the former case, spatial dependence is incorporated by including a function of the dependent variable observed at other locations on the right hand side. While this function can be very general, and even non-linear, it is typically simplified by using a spatial weights matrix. In the present context this implies that the benefit uptake rate in any particular LMA is assumed to be influenced by the benefit uptake rate in other LMAs, with more weight being given to those LMAs that are geographically closer to the LMA under consideration.

This approach can be extended to panel data, which is the case we are dealing with here (cross sectional data on benefit uptake pooled across the three censuses 1996, 2001 and 2006). Unfortunately, though the selection of the spatial weights matrix is a crucial aspect of a spatial econometric analysis, there exists no single preferred way of doing this weighting. The choice is often guided in practice by convenience, convention or rules of thumb (Griffith, 1996, p 65). In this paper the weights matrix is constructed on the basis of the reciprocal of the squared travel time between the major urban centres of pairs of LMAs. The matrix takes a block diagonal form. Effectively, this can be interpreted as there being an infinite distance between any LMA in a specific time period and all other LMAs at other points in time. Before carrying out spatial regressions, the weights matrix has been row standardised (i.e. across each row, the weights sum to one).

One further complication should be taken into account. This is the fact that the random errors in the regression equation for a particular benefit type are likely to be correlated over time and space with the errors of the regression equation for another benefit type. When the data are non-spatial, the Seemingly Unrelated Regression (SUR) model was proposed by Zellner (1962) to deal with crcss-equation correlation and this estimator is available in most econometric software. To combine this estimator with the estimator for the spatial regression model, a two-stage procedure was used. In the first stage, the spatial lag model was estimated for each equation (using Stata software). From this, the spatial lag parameter was retrieved for each equation. The predicted spatial spillover effect was calculated next, by multiplying the estimated spatial lag parameter by the spatially weighted average of the corresponding benefit take up rate. In the second stage regression, this predicted spillover effect was then added to the other regressors and the coefficients of the resulting SL-SUR model were calculated. Besides generating coefficient of all variables in all four equations of the SL-SUR model, this procedure also provides updates of the spatial lag parameters.

While the statistical properties of this procedure are not yet formally known, the results were quite stable and similar to those of various alternative models. This provides some confidence in the reliability and superiority of the statistical inference with the SL-SUR model.

Table 4 contains the results of the SL-SUR model. The first point to note is that the spatial lag obtained from the first stage regression is statistically significant for all 
benefit types. The estimated spatial lag parameter (a kind of partial correlation coefficient) varies between 0.148 for the sickness benefit uptake and 0.272 for the invalids benefit uptake. Essentially the significant spatial correlation suggests that, after controlling for various demand and supply factors that control for a variation in benefit uptake across LMAs, there remains a significant clustering due to unmeasured geographically-specific features. LMAs with high or low uptake rates are surrounded by similar LMAs.

Joint estimation with the SUR method results in upscaling of the spatial spillover effect for all four benefit types by a factor varying between 1.392 for the DPB to 2.139 for the sickness benefit. This upscaling is plausible. The SUR model - which accounts for the fact that when there is a high uptake of one type of benefit in a particular region, there is likely to be a high uptake of other benefits in that region as well - is going to give the influence of spatial clustering a more prominent role. The adjusted spatial lag parameter varies between 0.317 for the sickness benefit and 0.516 for the invalids benefit, and is statistically significant in all cases.

Table 4 clearly shows that the uptake of the four main social security benefits is positively correlated with the slackness of the local labour market, as measured by the lagged census unemployment rate of the LMA (lagpue). Benefit uptake is generally counter-cyclical (less uptake in a buoyant labour market) and there is evidence of hysteresis. In LMAs with high past unemployment, current benefit uptake is greater. As expected, these effects are the strongest for the unemployment benefit and the least for the DPB. Consequently, although there are many factors determining benefit uptake (for New Zealand, see e.g. Wilson et al. 2005), the present analysis reinforces the importance of the state of the local labour market. A 10 percentage point increase in the LMA census unemployment rate increases the proportion of the population age 15 to 64 receiving the unemployment benefit by about 5 percentage points and those on the sickness, invalids and DPB by about $1.4,1.7$ and 1.0 percentage points respectively.

Another factor, already clearly identified in the international literature and in New Zealand by for example Pool et al. (2006a), is the role of age composition (lagpoldwork). Table 4 shows that the presence of an older labour force increases the uptake of both the sickness and the invalids' benefits, as the jobs created over the last two decades often do not match the abilities of these workers. The uptake of DPB and the unemployment benefit are at the LMA level not significantly affected by the relative shares of older workers.

As expected, LMAs in which the local labour force is relatively unskilled (i.e. the highest percentages of workers with no qualifications, lagpnoqual) have a higher benefit uptake, although in the estimates reported in Table 4 this effect is not statistically significant in the case of the unemployment and sickness benefits. After controlling for age, the lack of skill will be a particularly important problem for workers who have been out of the labour market for a long time. Recipients of the invalids benefit and the DBP have in common a long average duration of benefit receipt, as compared with the other two benefits. For example, in September 2006, 45 percent of DPB recipients and 75 percent of invalids beneficiaries had been in receipt of some form of benefit for more than 4 years, compared to 30 and 16 percent of sickness and unemployment benefit receivers respectively.

While the results by Cochrane and Poot (2007) provided some support for the Oswald hypothesis of higher home ownership rates (lagpoprop) lowering geographic mobility rates and contributing to unemployment hysteresis, there is no evidence that in regions with greater homeownership there is higher benefit uptake. Couples, with or without children, are more likely to be homeowners than single persons with otherwise identical characteristics, but in the case of couples the unemployment benefit is not likely to be available to an unemployed person when there is a working partner. Consequently, the LMA homeownership rate may not affect benefit uptake. However, LMAs with relatively more family households rather than single-person households are also likely to have a relatively larger number of single parents. This is reflected in a small positive coefficient of homeownership in the DPB equation. As noted in the introduction, the other geographic mobility-related factor we considered is the rate of net migration over the preceding intercensal period (net_mig). However, this variable is statistically insignificant for all benefit types.

On the demand side of the labour market, most of employment growth has been in services (lagpservice). In LMAs where the service sector jobs are a larger proportion of total employment, the benefit uptake over the 1996-2006 period has been less. The effect is statistically significant for the unemployment and sickness benefits, but not for the other two types of benefits.

Because the vast majority of persons in receipt of the DPB are single parents, it is not surprising to find that the share of single parent families in all families is significantly and positively associated with the DPB uptake. This variable is also positive and significant in the equations for the sickness and invalid benefit rates. As expected, the coefficient is nonetheless the greatest in the DBP uptake equation. Even in the unemployment benefit equation, the coefficient is of plausible size, but not statistically significant. Generally, it is possible that lagpsolo is a proxy for broader set of conditions that correlate with ill health and labour market disadvantage. This perspective is supported by the relative prominence of single parenthood in New Zealand measures of community deprivation (see for example Salmond et al. 2006). 
Table 4: Determinants of benefit uptake - Results of the SL-SUR regression model.

\begin{tabular}{lcccccccc}
\hline & \multicolumn{2}{l}{ Unemployment benefit } & \multicolumn{2}{c}{ Sickness benefit } & \multicolumn{2}{c}{ Invalids benefit } & \multicolumn{2}{c}{$\begin{array}{c}\text { Domestic purposes } \\
\text { benefit }\end{array}$} \\
\hline & Coef. & $\mathrm{p}$-value & Coef. & $\mathrm{p}$-value & Coef. & $\mathrm{p}$-value & Coef. & $\mathrm{p}$-value \\
\hline initial spatial lag & 0.205 & 0.005 & 0.148 & 0.138 & 0.272 & 0.015 & 0.250 & 0.000 \\
SUR lag coefficient & 1.673 & 0.001 & 2.139 & 0.000 & 1.898 & 0.000 & 1.392 & 0.000 \\
adjusted spatial lag & 0.343 & 0.001 & 0.317 & 0.000 & 0.516 & 0.000 & 0.348 & 0.000 \\
lagpue & 0.521 & 0.000 & 0.138 & 0.000 & 0.166 & 0.000 & 0.103 & 0.000 \\
lagpoldwork & -0.027 & 0.793 & 0.140 & 0.000 & 0.131 & 0.008 & -0.006 & 0.871 \\
lagpnoqual & 0.015 & 0.692 & 0.014 & 0.216 & 0.104 & 0.000 & 0.041 & 0.001 \\
lagpoprop & -0.005 & 0.891 & -0.014 & 0.175 & -0.006 & 0.710 & 0.032 & 0.005 \\
net_mig & 0.008 & 0.557 & -0.003 & 0.431 & -0.012 & 0.068 & 0.004 & 0.442 \\
lagpservice & -0.064 & 0.040 & -0.024 & 0.009 & 0.011 & 0.479 & -0.016 & 0.127 \\
lagpsolo & 0.086 & 0.235 & 0.083 & 0.000 & 0.101 & 0.003 & 0.199 & 0.000 \\
lagpmaori & -0.011 & 0.661 & -0.021 & 0.003 & -0.065 & 0.000 & 0.002 & 0.824 \\
1996 & -0.067 & 0.901 & -0.139 & 0.347 & -0.450 & 0.103 & -0.068 & 0.683 \\
2006 & -0.2462 & 0.001 & 0.020 & 0.905 & 0.786 & 0.003 & -0.394 & 0.048 \\
constant & 2.142 & 0.417 & -1.291 & 0.093 & -6.535 & 0.000 & -4.548 & 0.000 \\
RMSE & \multicolumn{2}{c}{1.372} & 0.403 & & 0.656 & & 0.455 \\
Chi-squared & \multicolumn{2}{c}{1048.4} & 461.6 & & 397.2 & & 1785.5 \\
$R^{2}$ & 0.857 & 0.720 & & 0.692 & & 0.910
\end{tabular}

The results in Table 4 suggest that in LMAs with disproportionally large numbers of Māori, the sickness and benefit uptake rates are on average lower. This would seem inconsistent with the generally worse labour market outcomes experienced by Mãori, but at the regional rather than individual level this result can be explained by the markedly different age structures of the Māori and Pakeha populations. The Mãori population is much younger on average than the European population, whereas the sickness and invalid benefit uptakes are concentrated among older workers.

Table 4 shows that buoyant economic conditions nationally in 2006 (with 2001 being the reference point), led to a significantly lower uptake of the unemployment benefit and the DPB everywhere. However, at the same time the uptake of the sickness benefit and the invalids benefit was greater everywhere. As already noted in the introduction, this national trend does not reflect a deteriorating health of the population. Instead, it is due to a pervasive phenomenon in most developed countries: the sharp decline in the demand for blue-collar older workers, for whom job prospects are poor, unemployment has had a physical and emotionally scarring effect, and an incapacity benefit is only source of ongoing income. Since the increase in benefit uptake is a long-term trend (see also Figure 1), the 1996 dummy is negative relative to the 2001 reference point as expected, but interestingly - insignificant for all benefit types.

The SL-SUR estimates presented in Table 4 above are global in nature, in that the procedure yields unique parameter estimates for each equation and a form of spatial dependence in each equation that applies to all regions equally. In addition to spatial dependence, the possibility of non-stationarity of parameter estimates arising from spatial heterogeneity is also of interest. For instance, not all LMAs are likely to be equally influenced by surrounding LMAs. Highly accessible LMAs, say metropolitan areas with dense road nets and large concentrations of economic activity, will exert stronger effects on their neighbours than relatively isolated and peripheral regions (Longhi et al., 2006, p 723).

To account for spatial heterogeneity a number of locally linear spatial models have been developed, notably the geographically weighted regression (GWR) models (e.g., Brunsdon et al. 1996). A detailed discussion of the GWR estimator cannot be entered into here. The main distinguishing feature of the GWR methodology is the use of a distance-weighted sub-sample of observations to produce locally linear estimates for every point in space. This maybe thought of as analogous to a kernel density estimator

This GWR model was applied to the benefit uptake data. At present, this can only be done in a cross-sectional setting rather than in a panel setting. The results for the 1996, 2001 and 2006 cross sections indicate that the GWR model describes the data in a few instances in the 1996 and 2001 cross sections better than in global model. However, this does not hold true for 2006. It appears that the buoyant labour market conditions of 2006 coincided with a decrease in heterogeneity in modelling labour market and benefit uptake outcomes, although we saw earlier that the statistical dispersion of the distribution of outcomes across LMAs has in fact seen a long-term upward trend. An interesting by-product of tests of spatial 
heterogeneity was that five of seven instances of statistically significant spatial heterogeneity involved the lagged Māori variable. This suggests that the extent to which the Māori variable proxies for an unmeasured disadvantage or other ethnicity-related factors varies across regions of New Zealand. We noted earlier that the Mãori population is much more youthful than the nonMãori population, which can explain the negative coefficients in the sickness and invalids benefit equation, but at the same time there can be an interaction effect in that the Mãori population may be relatively more youthful in those LMAs where the non-Māori population is relatively older.

\section{Conclusion}

In this paper we investigated the extent to which the spatial-temporal variation in social security benefit uptake in New Zealand can be linked to compositional effects regarding the workers' human capital and demographic characteristics, the level and composition of labour demand, and the geography of local labour markets.

We found that during the economic boom and declining unemployment up to 2006, the uptake of the unemployment benefit and the DPB declined but that the secular increase in the uptake of the sickness and invalids benefit, also observed in many other countries, continued. Nonetheless, cross-sectionally, LMAs with lower unemployment rates had lower benefit uptake rates of all types. Moreover, across LMAs there is geographical clustering in benefit uptake. Ignoring this spatial correlation may lead to erroneous conclusions regarding the role of local conditions in explaining the regional variation in benefit uptake.

The uptake of sickness and invalids benefits is greater. but quantitatively similar, in LMAs where the labour force is relatively older. Several other features of LMAs affect benefit uptake also, such as qualifications, the composition of employment, household composition and ethnicity. However, the impact of these factors varies across benefit types.

We also accounted for spatial and temporal correlations in uptake across different types of benefits. However, there is little evidence of spatial heterogeneity, i.e. national regression coefficients are informative across LMAs. The only exception to this is the apparent spatial instability of the coefficient of the ethnicity variable. This issue warrants further investigation.

The major lacuna in the available variables is the lack of a 'health' variable. Although changes in the health status of the general population has been largely discounted in the literature as a major driver of changing benefit uptake levels (e.g. Bound and Burkhauser, 1999; Beatty et al., 2000: Alcock et al., 2003; Autor and Duggan, 2003; Faggio and Nickell, 2003), it would have been desirable to investigate this specifically within the New Zealand context. Future development of this research intends to incorporate such a variable, perhaps utilising the census question on smoking, or administrative and survey health data from the Ministry of Health.

\section{References}

Arbia, G. (2006). Spatial Econometrics. Berlin: Springer Verlag.

Alcock, P., Beatty, C., Fothergill, S., MacMillan, R., and Yeandle, S. (2003). Work to Welfare: How Men Become Detached from the Labour Market. Cambridge: Cambridge University Press.

Anselin, L. (1988). Spatial Econometrics: Methods and Models. Dordrecht: Kluwer Academic.

Autor, D. H. and Duggan, M. G. (2003). The rise in the disability rolls and the decline in unemployment. Quarterly Journal of Economics, 118, 157-206.

Baddeley, M., Martin, R. and Tyler, P. (1998). Transitory Shock or Structural Shift. The Impact of the early 1980's Recession on British Regional Unemployment. Applied Economics, 30, 19-30.

Bartik, T.J. (2002). Spillover Effects of Welfare Reforms in State Labor Markets, Journal of Regional Science, 42(4), 667-701.

Baxendine, S., Cochrane, B., Pool, I. and Poot, J. (2005). New Zealand Regions 1986-2004: Regional Social Security Benefit Usage and the Labour Market. Paper presented at the conference On the Frontiers: New Public Good Research on Population, Migration and Community Dynamics, March 30 - April 1, Wellington.

Beatty, C., S Fothergill and Macmillan, R. (2000). A theory of employment, unemployment and sickness. Regional Studies, 34(7), 617-630.

Beatty, C., S. Fothergill and Powell, R. (2007). Twenty Years On: Has the Economy of the UK Coalfields Recovered? Environment and Planning, A 39(7), 1654-1675.

Black, D., Kermit, D. and Sanders, S. (2002). The impact of economic conditions on participation in disability programs: evidence from the coal boom and bust. American Economic Review, 92, 27-50.

Bound, J. and Burkhauser, R.V. (1999). Economic analysis of transfer programs targeted on people with disabilities. In O. Ashenfelter and D. Card (Eds.), Handbook of Labor Economics (Vol. 3C, pp. 3417-3528). Amsterdam: North-Holland.

Brunsdon, C., A. S. Fotheringham and Charlton, M.E. (1996). Geographically weighted regression: A method for exploring spatial non-stationarity. Geographical Analysis, 28, 281-298. 
Chapple, S., and Rea, D. (1998). Time series analysis of disparity between Mäori and non-Mäori labour market outcomes in the Household Labour Force Survey. Labour Market Bulletin 1\&2, 127-144.

Cochrane, W. and Poot, J. (2007). Homeownership and the New Zealand Labour Market. In: PS Morrison (ed) Labour, Employment and Work in New Zealand - Proceedings of the Twelfth Conference. Wellington: Victoria University of Wellington.

Cochrane, W.R. (2010). Regional Diversity and Local Labour Market Outcomes in New Zealand. PhD Dissertation. Hamilton: University of Waikato.

Faggio, G. and Nickell, S. (2003). The rise in inactivity among adult men. In R. Dickens, P. Gregg and J. Wadsworth (Eds.), The Labour Market Under New Labour (pp. 40-52). Basingstoke: Palgrave Macmillan.

Gould, J. (2003). Mãori-Pakeha Occupational Segregation and Earnings Differentials: A Comment. New Zealand Population Review, 29(2), 1-10.

Goux, D. and Maurin, E. (2000). The Decline in Demand for Unskilled Labor: An Empirical Analysis Method and its Application to France. Review of Economics and Statistics, 82(4), 596607.

Griffith, D. (1996). Some Guidelines for Specifying the Geographic Weights Matrix Contained in Spatial Statistical Models. In S. Arlinghaus (Ed.), Practical Handbook of Spatial Statistics (pp. 6582). Boca Raton: CRC Press.

Kraft, K. (2001). Unemployment and the Separation of Married Couples. Kyklos, 54(1), 67-88.

Longhi, S., Nijkamp, P. and Poot, J. (2006). Spatial Heterogeneity and the Wage Curve Revisited. Journal of Regional Science, 46(4), 707-731.

Machin, S. (2001). The changing nature of labour demand in the new economy and skill-biased technology change. Oxford Bulletin of Economics and Statistics, 63(s1), 753-776.

McVicar, D. (2006). Why Do Disability Benefit Rolls Vary between Regions? A Review of the Evidence from the USA and the UK. Regional Studies, 40(5), 519-533.

MSD (2008). 2008: The Social Report. Wellington: Ministry of Social Development.

Newell, J.O. and Papps, K.L. (2001). Identifying Functional Labour Market Areas in New Zealand: A Reconnaissance Study using Travel-to-Work Data (New Zealand Department of Labour
Occasional Paper Series No. 2001/6). Wellington: Department of Labour.

Nickell, S. and Bell, B. (1995). The collapse in demand for the unskilled and unemployment across the OECD. Oxford Review of Economic Policy 11(1), 40-62.

Oswald, A. (1996). A Conjecture on the Explanation for High Unemployment in the Industrialized Nations: Part I. Warwick University Economic Research Paper No. 475.

Pehkonen, J. and Tervo, H. (1998). Persistence and turnover in regional unemployment disparities. Regional Studies, 32(5), 445-458.

Pool, I., Baxendine, S., Cochrane, W. and Lindop, J. (2006a). New Zealand Regions, 1986-2001: Dependency and Development of Social Capital. PSC Discussion Paper No 62. Hamilton: Population Studies Centre, University of Waikato.

Pool, I., Baxendine, S., Katzenellenbogen, J. and Howard, S. (2006b). New Zealand Regions, 19862001: Hospitalisation and some Related Health Facts. PSC Discussion Paper No 63. Hamilton: Population Studies Centre, University of Waikato.

Richards, M., Hardy, R. and Wadsworth, M. (1997). The effects of divorce and separation on mental health in a national UK birth cohort. Psychological Medicine, 27(5), 1121-1128.

Salmond, C., Crampton, P. and Atkinson, J. (2007). NZDep2006 Index of Deprivation. Wellington: Department of Public Health, University of Otago.

Stabler, J. C. and Olfert, M.R. (1996). Spatial Labor Markets and the Rural Labor Force. Growth and Change, 27(2), 206-230.

Stephens, B. (1992). Budgeting with the benefit cuts. In J Boston \& P Dalziel (Eds.), The Decent Society, Essays in Response to National's Economic and Social Policies. Oxford: Oxford University Press.

Tukey, J.W. (1977). Exploratory Data Analysis. Reading, MA: Addison-Wesley.

Vella, F. and Verbeek, M. (1999). Estimating and Interpreting Models with Endogenous Treatment Effects. Journal of Business and Economic Statistics, 17, 473-478.

Wilson, M., McLeod, K. and Sathiyandra S. (2005). Growth in Numbers of Sickness and Invalid's Benefit Recipients 1993-2002: Cohort Analysis Technical Report. Wellington: Centre for Social Research and Evaluation, Ministry of Social Development. 
Zellner, A. (1962). An Efficient Method of Estimating Seemingly Unrelated Regressions and Tests for Aggregation Bias. Journal of the American Statistical Association, 57, 348-368.

\author{
Authors \\ William Cochrane \\ Lecturer \\ Department of Societies and Cultures \\ University of Waikato \\ Private Bag 3105 \\ Hamilton 3240 \\ Billpsc@gmail.com \\ Jacques Poot \\ Professor of Population Economics \\ Population Studies Centre \\ Faculty of Arts and Social Sciences \\ University of Waikato \\ Private Bag 3105 \\ Hamilton \\ JPoot@waikato.ac.nz
}

